\title{
Four-wire Submerged Arc Welding Process with DC-AC Power Combination for Production of High Toughness Line Pipe*
}

\author{
By Zenroku BABA, ${ }^{* *}$ Matajiro NAGASHIMA, ${ }^{* * *}$ Mutsuo NAKANISHI, ${ }^{* * * *}$ \\ Norio KATSUMOTO ${ }^{* * * *}$ and Kazuo KAWAI*****
}

\begin{abstract}
Synopsis
The method for improving the weld metal toughness and new welding process for high speed welding have been investigated.

The formation of acicular ferrite microstructure is essential for high weld metal toughness, for which $\mathrm{Ti}-\mathrm{B}$ bearing low oxygen weld metal is needed.

Highly basic fused flux has been developed, which could mainlain low oxygen content in spite of increasing the welding speed.

To increase the welding speed, use of DC power supply for first arc is effective. Based on the knowledge for three-wire welding process, $D C$ $A C-A C-A C$ powered four-wire submerged arc welding process has been developed and applied for line pipe production, which contributed to high productivity and high quality.
\end{abstract}

\section{Introduction}

Multiple-wire submerged arc welding process has been used for production of longitudinally welded line pipes. In view of the demand for high productivity, two-wire or three-wire ${ }^{1,2)}$ submerged arc welding processes were commonly used for many pipe mills hitherto. Recently, four-wire submerged arc welding processes have been developed ${ }^{3-5)}$ for increasing welding speed still more.

On the other hand, line pipes for arctic use tend towards lower temperature service. According to these, higher weld metal toughness is also required. Though one factor to improve the weld metal toughness is lowering oxygen content, multiple-wire high speed welding causes the increase of the oxygen content. Therefore, high speed welding has the difficulty of satisfying high weld metal toughness. So, there is a task to solve these problems for putting high speed welding in pipe mills to practical use.

In this paper, the method for improving the weld metal toughness and appropriate welding process in high speed welding have been investigated.

\section{Improvement of Toughness of Submerged Arc Weld Metal in High Speed Welding}

\section{Factors to Improve Weld Metal Toughness}

Table 1 shows the factors to improve the weld metal toughness. ${ }^{6)}$ It is well understood that the uniform acicular ferrite is the most desirable microstructural feature in low alloy steel weld metal. The cooling rate is affected by plate thickness, heat input, preheating condition and so on.
Figure 1 shows the schematic illustration of WMCCT diagram, ${ }^{7}$ which is determined by the alloying and impurity gas elements, and this diagram is effective means to predict a microstructure in weld metal. The region of acicular ferrite (AF) formation is affected by heat input, alloying element, and oxygen content. This figure makes it possible to select the welding materials and welding conditions for producing acicular ferrite microstructure.

Photograph 1 shows an example of acicular ferrite microstructure, which is characterized by small grain size and high angle grain boundaries.

Ti-B bearing weld metal is essential for producing acicular ferrite microstructure, because titanium oxide acts as the nucleation sites of acicular ferrite, and boron could lower the free energy of austenite grain boundary and results in the suppression of grain boundary ferrite formation. But oxidation of boron weakens above effect. Therefore, the reducing of oxygen content is necessary to form uniform acicular ferrite in $\mathrm{Ti}-\mathrm{B}$ bearing weld metal.

Figure 2 shows the effect of oxygen level on the optimum $\mathrm{Ti}$ content for $\mathrm{Ti}-\mathrm{B}$ bearing weld metal. The optimum $\mathrm{Ti}$ content shifts to lower levels with decreasing oxygen level in weld metal.

Low temperature toughness of welds is plotted against the oxygen content in Fig. 3. It is clear that decreasing oxygen content in weld metal improves the low temperature toughness. It is well understood that the oxygen content in submerged arc weld metals is influenced by flux type and welding conditions.

Table 1. Factors to improve weld metal toughness.

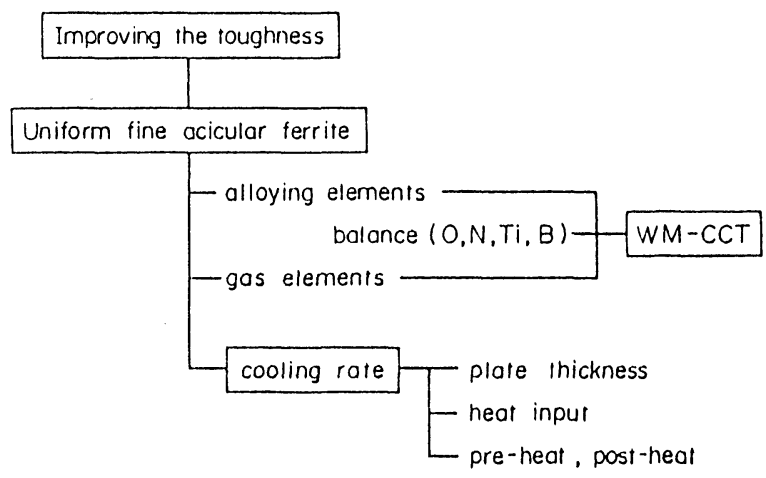

\footnotetext{
* Based on the paper presented to the 105th ISIJ Meeting, April 1983, A61, at The University of Tokyo in Tokyo. Manuscript received on August 15, 1985; accepted in the final form on November 1, 1985. (C) 1986 ISIJ

** Head Office, Sumitomo Metal Industries, Ltd., Kitahama, Higashi-ku, Osaka 541.

*** Kashima Steel Works, Sumitomo Metal Industries, Ltd., Oaza Hikari, Kashima-cho, Kashima-gun, Ibaraki 314.

**** Gentral Research Laboratories, Sumitomo Metal Industries, Ltd., Nishinagasu-hondori, Amagasaki 660.

***** Wakayama Steel Works, Sumitomo Metal Industries, Ltd., Minato, Wakayama 640.
} 


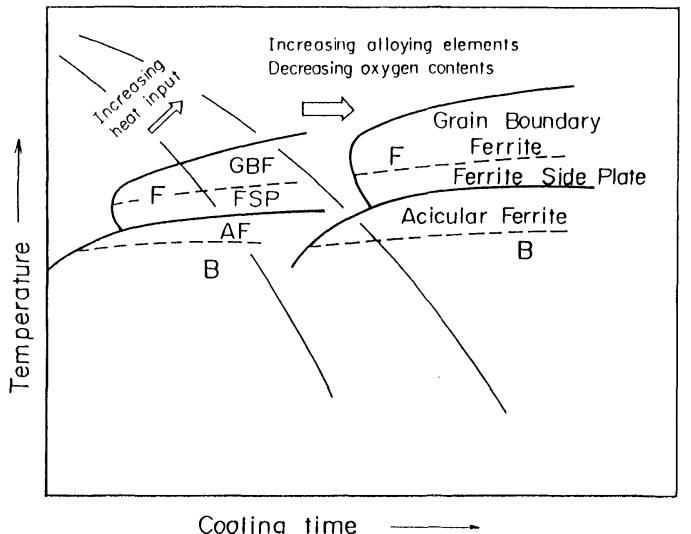

Fig. 1. Schematic illustration of WM-CGT diagram.

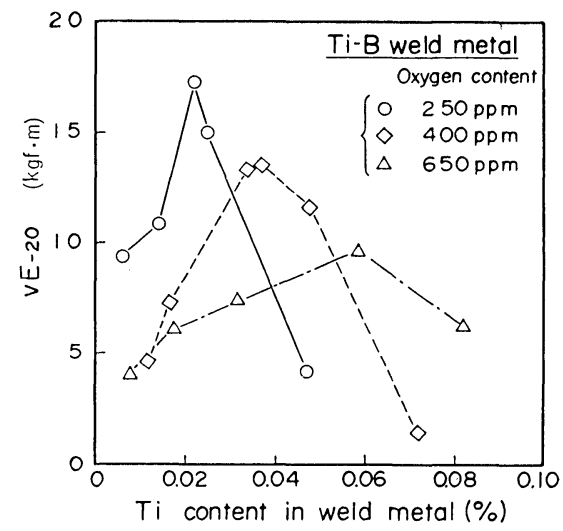

Fig. 2. Effect of oxygen level on optimum Ti content.

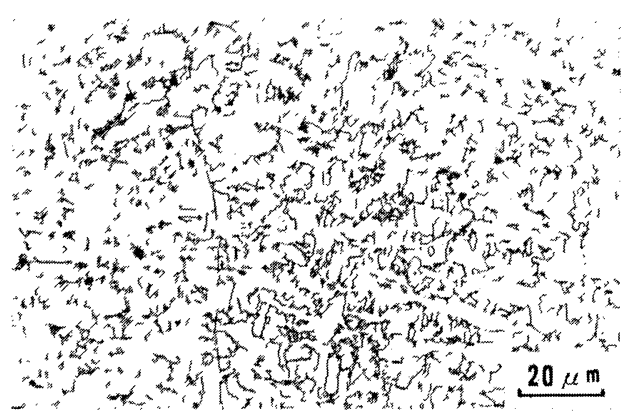

Photo. 1. An example of acicular ferrite microstructure.

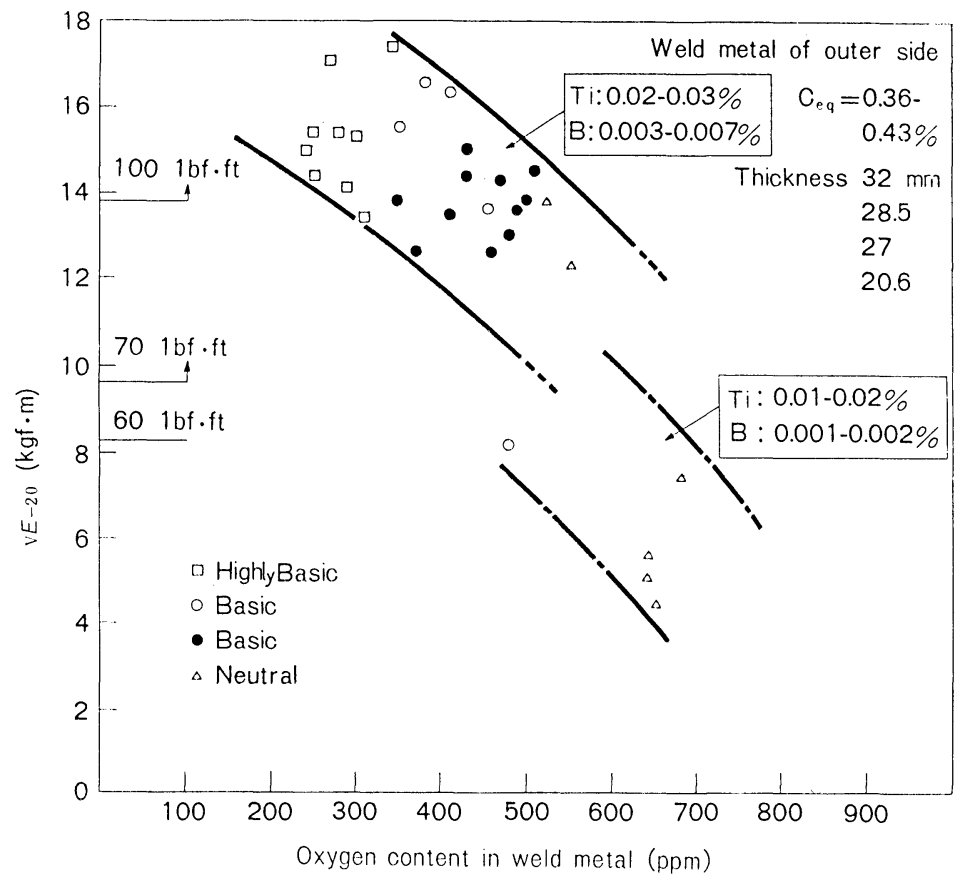

Fig. 3. Relationship between oxygen content and weld metal toughness.

The toughness of $\mathrm{Ti}-\mathrm{B}$ bearing weld metal is affected by not only oxygen content but also other elements such as Mn, Mo and so on.

Figure 4 shows the effect of carbon equivalent on the toughness of $\mathrm{Ti}-\mathrm{B}$ bearing weld metals for various oxygen levels. The weld metal toughness is improved at optimum carbon equivalent range. Poor toughness for less alloying content is based on the formation of coarse grain boundary ferrite, and the upper bainite is apt to form for high alloying contents. Also this figure indicates that the effect of oxygen content as well as the alloying elements should be taken into consideration in discussion of weld metal toughness.

\section{Effect of High Speed Welding on Impurity Gas Elements}

The toughness of submerged arc weld metal is remarkably affected by the oxygen content introduced by the welding flux.

Figure 5 shows the relationship between the welding speed and oxygen content in three-wire submerged arc weld metal for some flux types. Highly basic flux

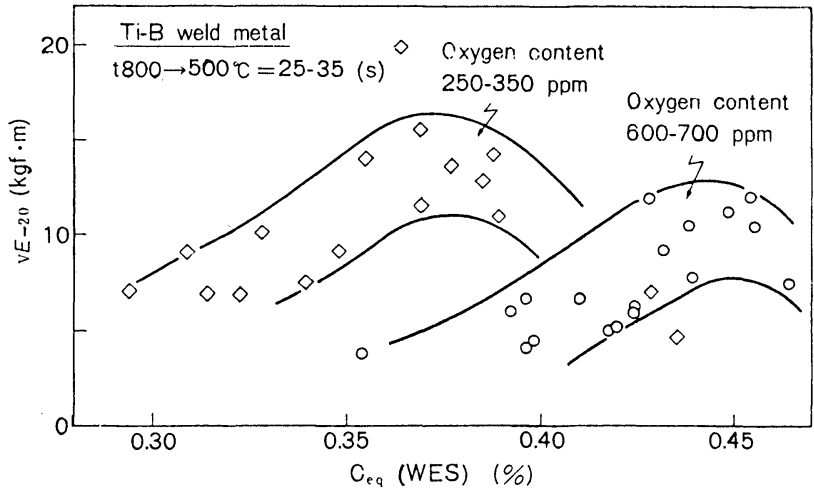

Fig. 4. Effect of carbon equivalent on toughness of Ti-B bearing weld metal.

gives the lowest oxygen levels inspite of increasing welding speed. Here, it is important that the oxygen content increases with an increase in the welding speed. In order to obtain high efficiency in the production of longitudinally welded pipes, high speed 


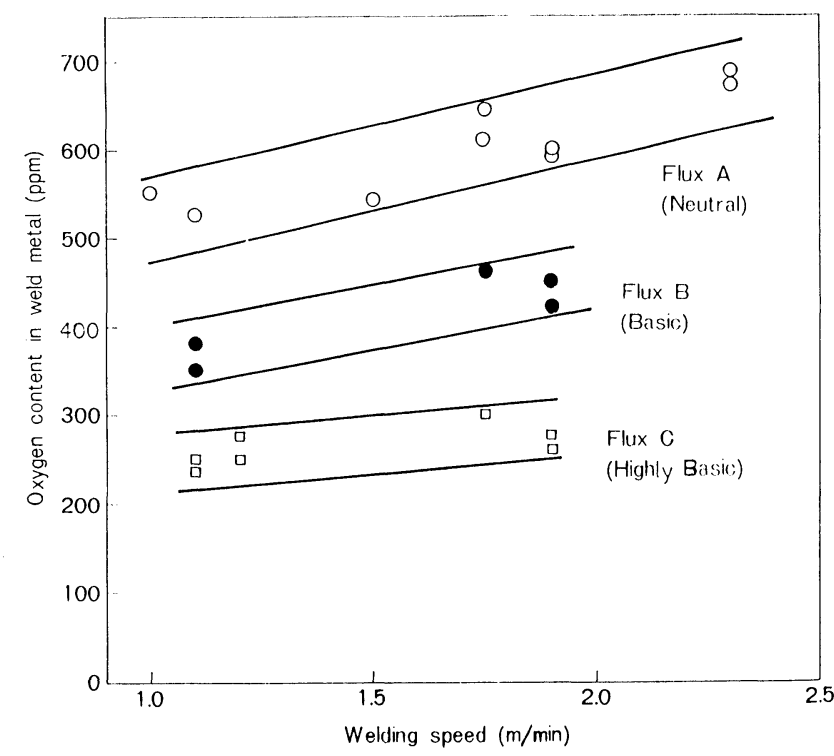

Fig. 5. Relationship between welding speed and oxygen content.

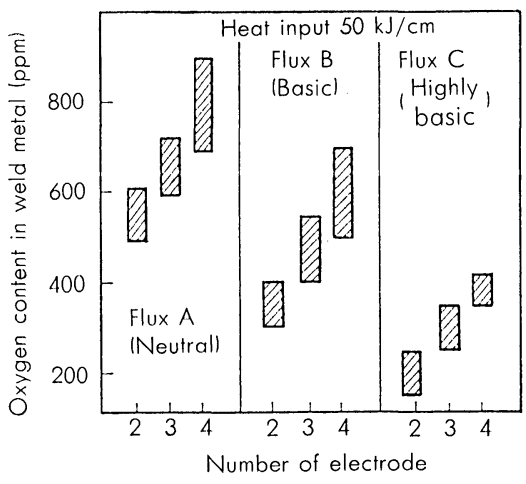

Fig. 6. Relationship between number of electrode and oxygen content.

multiple-wire submerged arc welding process has been used. But, this tendency seems to cause a problem in view of improving weld metal toughness.

Figure 6 shows the relationship between number of electrode and oxygen content in weld metal. It is clear that the increase in the number of electrode causes an increase in oxygen content.

Figure 7 shows the relationship between heat input and impurity gas elements in four-wire submerged arc weld metal. Both oxygen and nitrogen content is higher in high current (high speed) than in low current (low speed) under the same heat input. Especially, nitrogen in weld metal is considered to be derived from the air contamination during welding. Therefore, it could be estimated that the increasing of oxygen and nitrogen content is due to the enlargement of the weld pool as increasing the welding speed.

Therefore, in order to obtain high toughness weld metal in high speed welding, it is essential to use the highly basic flux from the view point of lowering oxygen content.

Figure 8 shows the relationship between flux basicity $B_{L}$ of several fluxes and oxygen content. It is

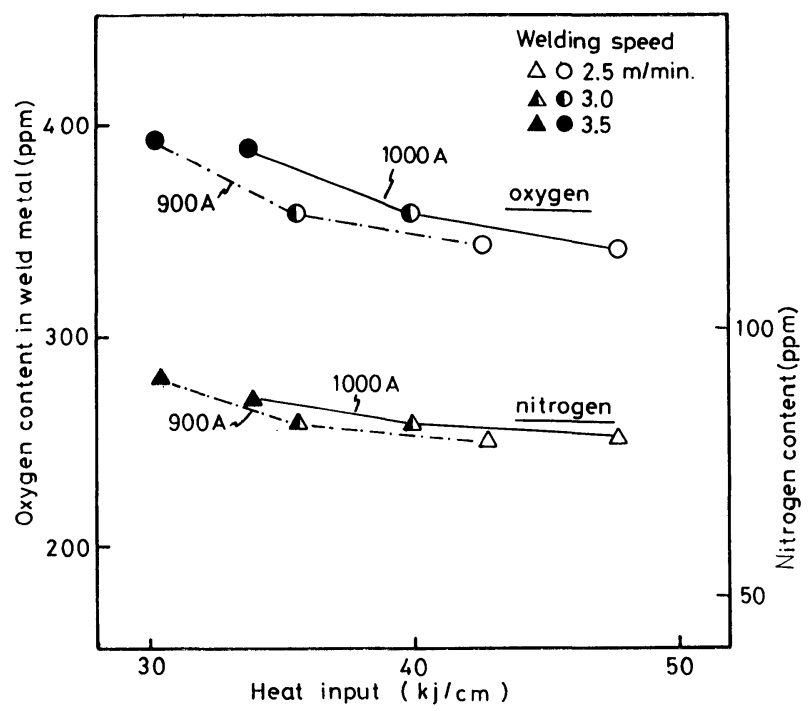

Fig. 7. Relationship between heat input and gas content in four-wire submerged arc weld metal.

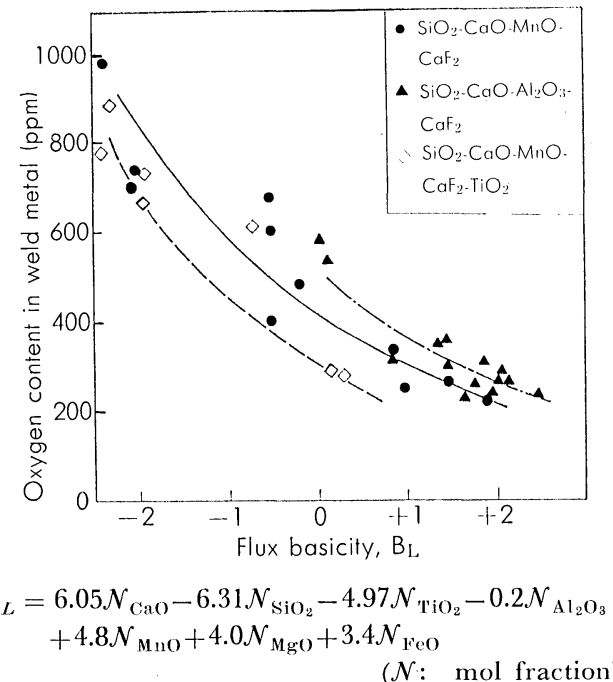

Fig. 8. Relationship between flux basicity $\mathrm{B}_{L}$ and oxygen content.

clear that the oxygen content decreases as flux basicity increases.

Also, the welding is required of good operative weldability such as bead appearance, and absence of weld defect and so on. In the consideration above, fused flux which consists of $\mathrm{SiO}_{2}, \mathrm{CaO}, \mathrm{Al}_{2} \mathrm{O}_{3}$, and $\mathrm{CaF}_{2}$ has been developed.

By using the developed flux, it could be possible to reduce oxygen content less than $300 \mathrm{ppm}$ in high speed welding.

\section{Four-wire Submerged Arc Welding Process}

1. Effect of DC Power Supply on the Penetration Depth in High Speed Welding

The problem of high speed welding is how to maintain a suitable penetration depth for double side welding. One weld is made on the inside and the other on the outside of the longitudinal joint. Therefore, some deep penetration is needed for increasing the 
welding speed. In view of these points, selection of the kind of power supply for high speed welding has been investigated.

Figure 9 shows the effect of DG (Direct Current) power supply on the penetration depth in three-wire submerged arc welding under the same current condition. By applying DC power supply to lead electrode, the penetration depth becomes larger than the case of all AG (Alternative Current) power supply. Therefore, it is expected that the use of the combination of DC-AC-AG power supply could be effective to increase the welding speed.

Photograph 2 shows the cross sectional change of weld bead when three arcs are switched on successively. By using DG power supply, especially the penetration depth of the first arc seems to be deeper than the case of the AC power supply.

Figure 10 shows the effect of DG power supply on heat input under the condition that the penetration depth keeps $60 \%$ of wall thickness. It is clear that the heat input could be reduced for same wall thickness by using the DG power supply. This effect becomes remarkable with an increase in the plate thickness. Also, the reduction of the heat input is effective for the improvement of HAZ (Heat Affected Zone) toughness.

Three-wire submerged arc welding process using DG-AC-AG current has been used in our mills, and

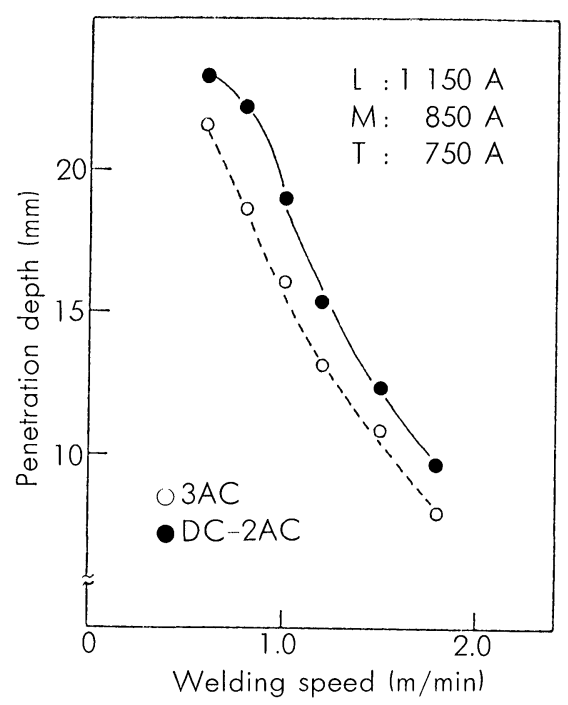

Fig. 9. Effect of DG power supply on penetration depth in three-wire submerged arc welding.

(bead on olate $t=191 \mathrm{~mm}$ )

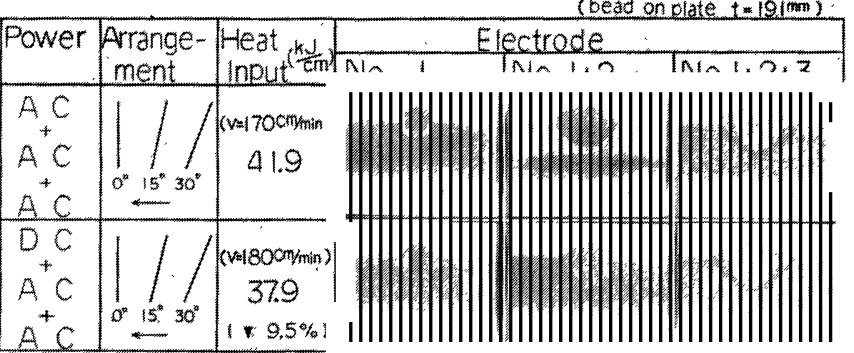

Photo. 2. Cross sectional change of weld bead. has had no problem on the quality of welds. To increase the welding speed for much productivity, four-wire submerged arc welding process has been investigated based on the above results concerning the three-wire welding process.

\section{Development of Four-wire Submerged Arc Welding Process}

As mentioned above, four-wire submerged arc welding process was investigated by adding a fourth $\mathrm{AC}$ electrode to three-wire $\mathrm{DG}-\mathrm{AC}-\mathrm{AG}$ welding process.

One problem of multiple-wire welding process is a transformer connection which is well known as the important factor to form the good bead shapes in high speed welding. Especially, when the last arc for multiple-wire welding is deflected forward, superior welds are produced.1,4,5,8) Based on the above, electromagnetic force on the fourth arc was calculated by the equation presented by Nomura et al. ${ }^{8)}$

Figure 11 shows the calculated electromagnetic force acting on the fourth arc in several phase sequence. Connection B shows a electromagnetic force in the welding direction, and it's validity was confirmed by the investigation of under cutting rate and bead shape of the actual welding. Therefore phase sequence of $\mathrm{AC}$ power supply has been set as follows, i.e., the second and fourth arc current are directly in phase, and the third arc current lags both by 120 electrical degree.

Figure 12 shows the relationship between welding speed and plate thickness in multiple-wire submerged arc welding process. Welding speed of DC powered

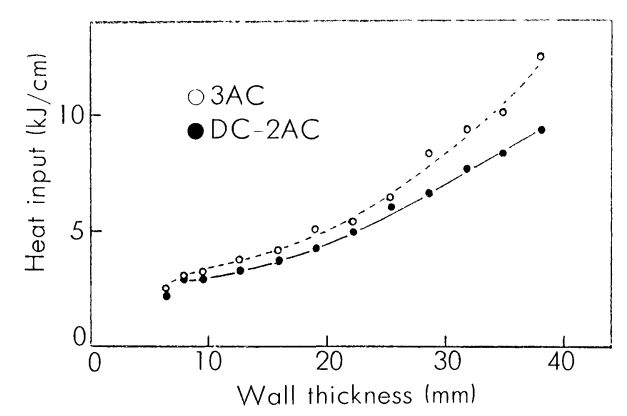

Fig. 10. Effect of DC power supply on heat input.

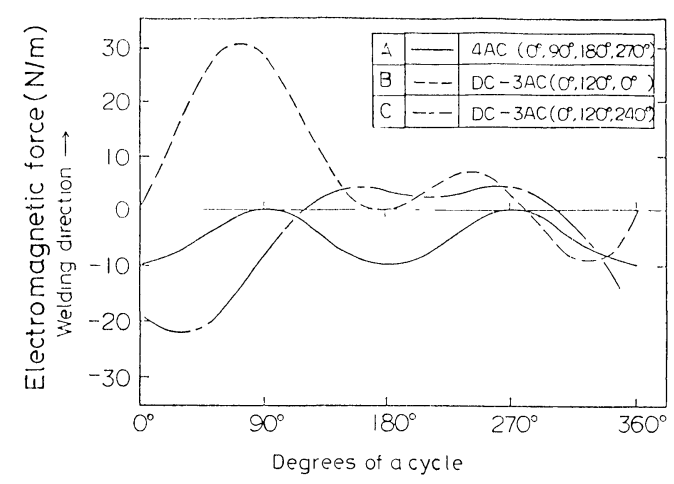

Fig. 11. Calculated electromagnetic force on fourth arc of four-wire submerged arc welding. 


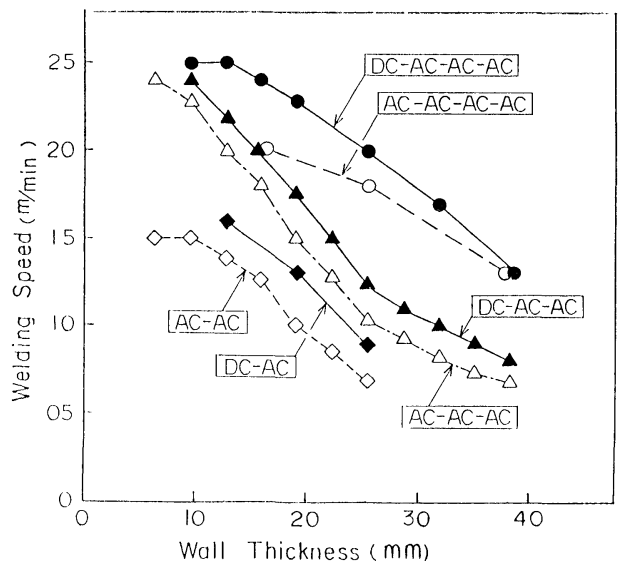

Fig. 12. Comparison between welding speed and wall thickness in multiple-wire submerged arc welding process.

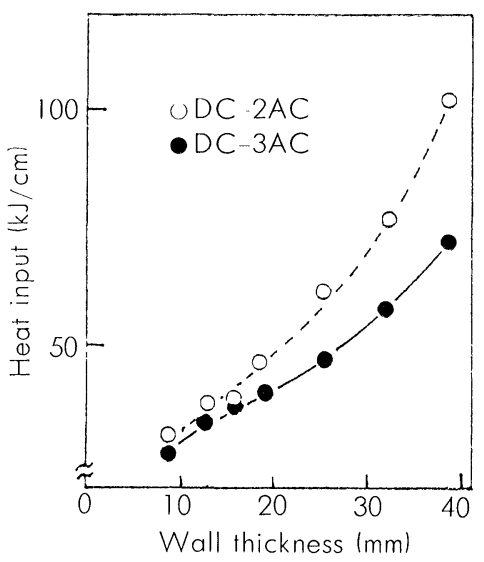

Fig. 13. Comparison of heat input between three-wire and four-wire welding proccss.

four-wire welding process represents about $85 \%$ (plate thickness $1.5 \mathrm{inch}$ ) and $65 \%$ (1 inch) increase over the three-wire welding process. This effect becomes large with increasing plate thickness.

Figure 13 shows the comparison of heat input between three-wire and four-wire welding process. From this figure, the reduction of heat input by using fourwire submerged arc welding process is possible compared with three-wire welding process.

\section{Application of Four-wire Submerged Arc Welding for Line Pipe Production}

Photograph 3 shows the weld cross sections for 15.8 $\mathrm{mm}$ wall thickness pipe compared four-wire with three-wire submerged arc welding, however, both inside were welded by three-wire welding process. The welding conditions were as follows;

Four-wire submerged arc welding

first $\quad 900 \mathrm{~A}-40 \mathrm{~V}$

second $900 \mathrm{~A}-42 \mathrm{~V}$

third $\quad 800 \mathrm{~A}-45 \mathrm{~V}$

fourth $\quad 800 \mathrm{~A}-48 \mathrm{~V}$

Three-wire submerged arc welding

first $\quad 1050 \mathrm{~A}-38 \mathrm{~V}$

second $800 \mathrm{~A}-46 \mathrm{~V}$

$1.7 \mathrm{~m} / \mathrm{min}$

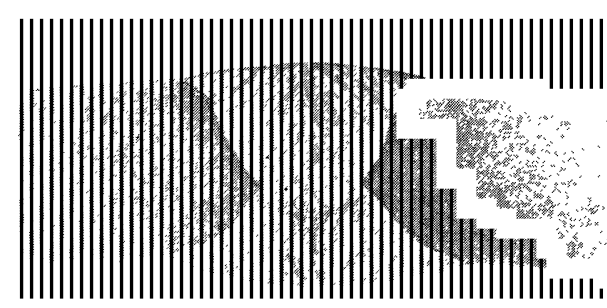

a

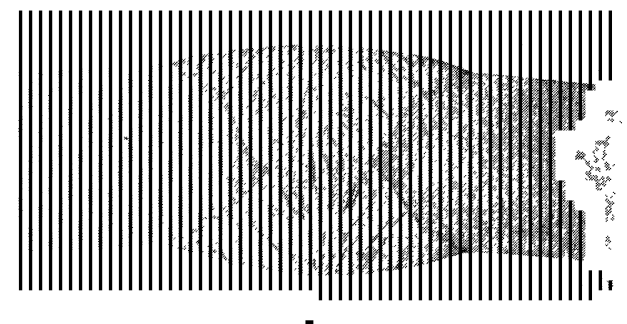

(a) Four-wire submerged arc welding

(b) Three-wire submerged arc welding

Photo. 3. Weld cross sections for $15.8 \mathrm{~mm}$ wall thickness pipe.

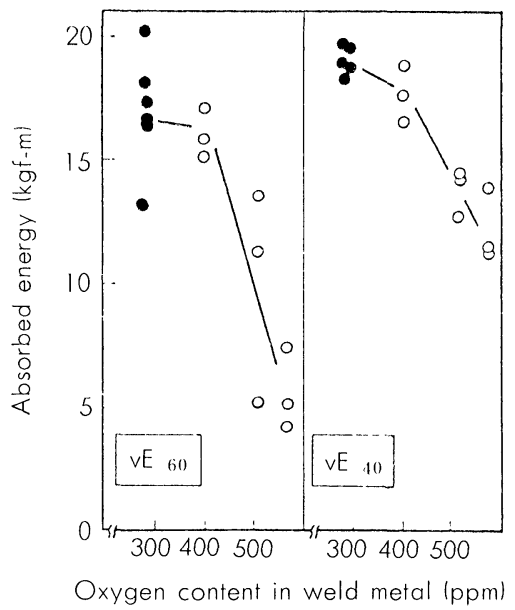

Fig. 14. Relationship between oxygen content and toughness of weld metal.

third $750 \mathrm{~A}-48 \mathrm{~V}$

Highly basic fused type flux was used. From the sectional area of weld bead, the possibility to reduce the heat input by using four-wire welding process could be estimated.

Figure 14 shows the relationship between oxygen content and toughness of weld metal in four-wire submerged arc welding. In this figure solid and open mark shows a newly developed highly basic flux and conventional flux, respectively. By using developed flux, high toughness could be obtained, which is derived from reduction of oxygen content less than 300 ppm.

Table 2 shows an example of weld metal toughness of line pipes produced by four-wire welding process. High weld metal toughness was achieved by lowering oxygen content and controlling alloying elements.

The four-wire submerged arc welding process has been applied for production of line pipes in our mill, 
Table 2. An example of toughness of weld metal.

\begin{tabular}{l|c|c|ccc}
\hline \multirow{2}{*}{ Steel } & \multirow{2}{*}{$\begin{array}{c}\text { Heat } \\
\text { input }\end{array}$} & $\begin{array}{l}\text { Oxygen } \\
\text { content }\end{array}$ & \multicolumn{3}{|c}{ Absorbed energy } \\
\cline { 3 - 5 } & & $v E-20$ & $v E-40$ & $v E-60$ \\
\hline $\begin{array}{l}\mathrm{X}-65 \\
\mathrm{t} 20 \mathrm{~mm}\end{array}$ & $\begin{array}{l}41000 \\
\mathrm{~J} / \mathrm{cm}\end{array}$ & $\begin{array}{l}280 \\
\text { ppm }\end{array}$ & $\begin{array}{l}19.2 \\
\text { kgf-m }\end{array}$ & $\begin{array}{l}19.2 \\
\text { kgf-m }\end{array}$ & $\begin{array}{l}16.7 \\
\text { kgf-m }\end{array}$ \\
\hline
\end{tabular}

and contributed to high productivity and high quality.

\section{Conclusion}

The method for improving the weld metal toughness and high speed welding in high productivity of line pipes have been investigated. Results obtained are summarized as follows;

(1) Acicular ferrite is regarded as being the most desirable microstructure from a toughness point of view. Ti-B bearing low oxygen weld metal is essential for producing the acicular ferrite structure.

(2) Oxygen content in weld metal increases as welding speed becomes high. Highly basic flux has been developed which could maintain low oxygen content inspite of increasing the welding speed.

(3) To increase the welding speed, use of DG power supply for the first arc of multiple-wire welding is effective. Additionally, decrease of the heat input could be achieved with use of DC power supply.

(4) DC-AC-AC-AC powered four-wire submerg- ed arc welding process has been developed. The optimum phasing sequence of $\mathrm{AG}$ was determined theoretically and practically as $0-120-0$.

(5) Welding speed of the four-wire submerged arc welding represents about 65 to $85 \%$ increase over the three-wire welding process.

(6) Four-wire submerged arc welding process has been applied to line pipe fabrication, which contributed to high productivity and high quality.

\section{REFERENCES}

1) G. D. Uttrachi and J. E. Messina: Welding J., 47 (1968), 475-481.

2) K. Akahide, K. Agusa, T. Ukebe and J. Tsuboi: IIW Doc. XII-A-155-78, 1978.

3) "Mannesmann large diameter pipe" Technical information, 1977.

4) B. van Berlekom, U. Dilthey and M. Mursic: IIW Doc. XII-A-180-80, 1980.

5) T. Yamaguchi, A. Shiga, A. Kamata, F. Kawabata and T. Uegaki: 89th Welding Process Research Committee of JWS, SW-1374-82, September 1982, (in Japanese).

6) M. Nakanishi and Y. Komizo: The Sumitomo Search, (1983), No. 28, 53-71.

7) Y. Ito, M. Nakanishi and Y. Komizo: Metal Construction, 14 (1982), 472-478.

8) H. Nomura, Y. Sugitani and H. Nakazawa: IIW Doc. XII-A-166-79, 1979. 